\title{
Quality of life: does measurement help?
}

\section{J. Bergsma ${ }^{1}$ and G.L. Engel ${ }^{2}$}

${ }^{1}$ Department of Medical Psychology, State University of Utrecht, The Netherlands and ${ }^{2} \mathrm{Health}$ Council of The Netherlands, The Hague, The Netherlands

\section{Summary}

'Quality of life' is a very frequently applied concept nowadays. One may doubt whether everyone has the same connotation in mind while using this expression and why 'quality of life' attracts so much attention. Is the idea a very old one or is it a new and noble value? It is argued here that changes such as in the number of aged people and of chronically disabled people, combined with spectacular developments in medical technology and with a rise in knowledge and assertivity, created an increased awareness of 'quality of life' and its interaction with medicine. Moreover, limitations to budgets and technological developments trigger an interest in new arguments. 'Quality of life' plays an increasing role in all sorts of medical decisions, be it in policy decisions or in individual clinical decisions, be it formally assessed or implicitly weighted. A number of examples is briefly described to illustrate the very broad and diffuse use of quality of life as a criterion. Subsequently we have tried to operationalize the concept on 4 levels: macro, meso, personal and physical. The macro level applies to the meaning of life in a society; assessments of quality of life play a role, for instance, in discussions on euthanasia and in political decisions on medical investments. Examples of the meso level are the hospital, with its internal processes and its ties to the rest of the world, but also the patient in his social environment. On the personal level the individual's frames of reference on health, IIIness, future, pain and hope - both of the patlent and the doctor - are being considered. It is argued that legitimation of important decisions, investments and interventions requires measurement of quality of life in an objective way and on different levels. Quantifying quality, however, appears hardly feasible. Therefore 'quality of life' is frequently measured at the fourth level only, the level of physical activities. Confining measurement to the measurable induces the question of whether it really is 'quality of life' that is being quantified. Still, results from such measurements can be of help in decision making. Who decides in clinical situations and in what way should 'quality of life' be involved in decision making? In one solution,

Address for correspondence: Dr. G.L. Engel, Health Council, P.O. Box 90517, 2509 LM The Hague, The Netherlands. 
perhaps the old fashioned one, the doctor takes all responsibility, possibly from a paternalistic ideal. Conversely, should the doctor behave in a completely non-directive way, full autonomy is given to the patient. We advocate a third way, where mutual respect of patient and doctor may enable open consideration of objective and subjective elements of 'quality of life' so as to give it a central place in clinical decisions.

Quality of life; Measurement; Autonomy

\section{Introduction}

As long as people have been able to reflect on their life, the quality of this life has not only been the central focus but also the generating inspiration of movements and changes. This counts for individual as well as for collective life. Existential quality has been and is the root of religions and wars, development of physical safety as well as civilization processes.

Let it not be suggested that 'quality of lifc' is a ncw discovery or a new noble value. Maybe the explicit formulation is new, maybe the way this expression is used or even misused today is new.

What might be the reason for such an idea, old as mankind itself, getting so much attention and new verbalization? Why does it elicit so many articles, editorials and even research institutes?

In this article we discuss some of the possible reasons for this renewed interest, the way 'quality of life' has been used so far and may be (mis)used in the future and the ways this idea may be of help in clarifying some of our problems in today's society.

It is a basic psychological law that changing signals attract more attention than consistencies. If so much attention is given to the issue 'quality of life' it seems to be a reasonable assumption that 'something' is changing and has been changing. In 1975 one of the first books published with a 'Quality of Life' title, was written by Anselm Strauss [1]. He did not define the concept but gave attention to chronic illness and ageing. So many people getting older and older was a new phenomenon in a socicty unprepared for this development. Pcople not only grew older but, consequently, many patients suffering from chronic diseases survived for more years than ever before. It is not a coincidence that in the same decade new technologies became available to treat severe afflictions like cancer, organ and system diseases. Chemotherapy and transplantation techniques increased survival rates, sometimes impressively. Improvement of social welfare, considerable investments in research and a fast-growing health care infrastructure, available for a broad spectrum of people, supported these developments.

These developments are also responsible for their side-effects: increasing costs for social and medical care and shifts in society's general financial resources.

In addition, the increase of Western affluency created more opportunities to im- 
prove the education of many, and the post-World War II climate created waves of democracy. Together they created a public with more knowledge, assertivity and awareness of their individual autonomy.

Considering this historical development we are facing an increasing awareness of life's qualities in a growing number of people. However, the expanded survival of many more chronic patients, the increase of the number of aged people up to higher ages and the successes of medical technology, creating standards of life and living we never knew before, confronted Western society with the coin's ethical reverse side. A general development with two faces created the 'change in signal' triggering our alertness. Which concrete topics may be observed related to this general tendency?

(1) About 20 years ago the world was confronted with far-reaching questions about the relation between medical technology and medical power. In Europe Van den Berg [2] confronted people with the far-reaching, extreme consequences of medical technology. In the U.S.A. Duff and Campbell [3] for the first time questioned the prolongation of life of severely handicapped newborns and created the same kind of embarrassment.

(2) The increasing survival of so many chronically diseased and severely handicapped patients stimulated the development of institutions and social facilities and consequently meant an explosive burden on societies' financial resources.

(3) The increasing number of aged people stressed the necessary medical infrastructural and social (care) facilities.

(4) The increase in possibilities to treat the main killers (cardiovascular disease and cancer) created a constant call for more research (more funds). At the same time ethical questions about the acceptability of different levels of human life before, during and after treatment were raised.

(5) Transplantation as a relatively new medical development raised the problem of gigantic technological and financial investments. The restricted availability of organs raised ethical debate about humane selection. The technology of transplantation and the development of new medications, among others, demand money, research, care, cure, educational facilities, professional people and organisational structures. The affluent and assertive patient claims his rights for treatment.

One may come to the conclusion that the whole problem of 'quality of life' is located within this triangle:

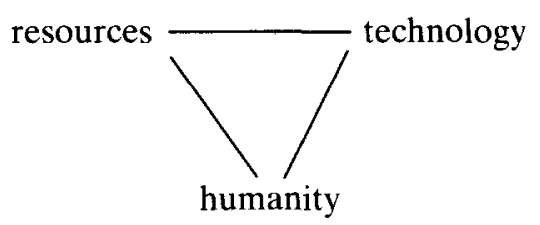


From the general historical development and subsequent concrete items it may be clear that 'tension' is the main idea fitting the triangle resources-technology-humanity together. However, it must be considered that although there is a tight togetherness between the 3 poles, they have unequal strength. To complicate things, strength shifts from situation to situation and from perception to perception and so the interaction has a variety of outcomes. It still seems to be a taboo to make connections between financial considerations and humanitarian values. Studies on these topics should make the link, but those who explicitly do so may encounter sharply formulated criticism. The connection between technology and humanity is much easier because it is still fashionable to sell technology as a gift to humankind, only meant for its well-being. The relation between technology and resources seems to be rather neutral and acceptable as long as we are willing to forget the individual human being in the middle of our abstract triangle. This person, for example, discovers how technology is not only meant for humanitarian well-being but also for accumulating profits. Human lives not only cost lots of money. They also provide a solid foundation for financial profit.

This discovery raises questions for the person in the middle: what is the value of my life, who is profiting from the continuation of my life and whose values are dominant in which decisions. Rephrasing these questions results in: whose interest is the determining factor in relation to 'quality of life': the patient and his illness, the physician, the budget controller, the policy maker or the shareholder. Probably they are all interested, but their interests do not coincide with each other.

Literature gives a nice chronological picture of how interests developed. The first publications raised ethical and social questions regarding neonatology, ageing people and extremely disfigured and crippled patients. The focus shifted to the dehumanizing treatments of cancer patients. An important concern now is transplantation and its consequences. A remarkable shift in focus to younger people may thus be seen. Attention for the quality of life of elderly, chronically ill and life-long crippled patients is fading away. Patients with a certain economic value tend to sneak to the center of the focus.

This does not at all imply that the problems formulated before are diminishing. On the contrary, problems of patient selection, life perspective, survival, resocialisation, job fulfillment are even more urgent. Just because technology can be applied to a group of still 'interesting' people, the call for objectivity increases. In other words, the connection between investments (in general) and profit (in general) is more than just intuitive decision making. Today's developments demand 'objective' measurements to legitimate investments in ongoing development of technology and the protection of the sanctity of humanity. Just one minor problem is left. Investments are countable. Technology is measurable in quantities and potentials. But how about humanity? Medicine and social sciences finding each other in something called 'behavioral medicine' initiated the developing of measurements of humanity. Research is still in progress but this initiative did not succeed. Too much (subjective) humanity is implicitly included in the concept 'quality of life'. Anselm Strauss [1] did not try to define 'quality of life'. Until now nobody succeeded in a definition. 
We can now summarise this introduction: this is a study about the need for measurement of the undefinable. In the following parts, though, it is shown that the problem is not as simple as that.

\section{Decision making}

It is generally accepted that assessments of the quality of life may play a role in decision making in health care. This applies to different levels of decisions and to different ways of assessment. Judgements and decisions are being made by policy makers (government, hospital), by doctors referring or treating patients and by patients themselves. Assessments may be rather formal, be it in controlled studies or in individual cases, but more usually they are rather implicit. To illustrate the enormous variety of ways of judgement and its underlying motives we will mention a few short examples ${ }^{1}$.

Renal transplantation has often been compared with (one of more ways of) chronic dialysis. Either modality aims at treating uremic end stage renal failure patients and both are, as a rule, rather successful in preventing complications of endstage renal insufficiency. Numerous studies have addressed quality of life during dialysis and after transplantation, many of those even on long-term. Most investigators have shown that quality of life after renal transplantation, if the graft is not rejected, is superior to that of dialysed patients. Consequently, most Western governments stimulate renal transplantation, notwithstanding the ethical and logistic problems associated with transplantation programs. In The Netherlands, for instance, renal transplantation is the only top-clinical program not suffering from budgetary limits [4]. Admittedly, it has also been shown that the cost per patient decreases when dialysis can be replaced by transplantation [5].

Hip replacement is another costly, but common, treatment in most Western countries. The operation is not performed to prolong life, but to free the patient from chronic or episodic pain and (partial) immobility. One might say that the one and only motive is to improve quality of life. Since this increase has been shown to be so impressive, costs of hip replacement are routinely reimbursed, although this is usually confined to a maximum number of operations per centre. In this example assessment of quality of life not only plays a role on the policy level, but very strongly also in individual cases. The doctor tries to judge the patient's complaints and mobility and finds out whether an indication exists and, if so, whether an operation is urgent or should be postponed. In doing so, the doctor will try to compare this individual patient with other patients he knows of. Perhaps the eventual decision may be affected by the doctor's waiting list also. The individual patient's judgement plays an important role, since he or she formulates the complaints. So, in hip replacement, various assessments of quality of life are essential both to the establishment of the program at large and to individual treatment. On

${ }^{1}$ In order to restrict the argument to space limits, the medical descriptions are necessarily rather short and straightforward. 
the whole, however, these assessments are rather subjective and implicit.

Local treatment of breast cancer can be a radical operation (mastectomy) or brcast sparing treatment. In the former case, the complete breast is removed, in the latter only the tumor is taken away and the rest of the breast is conserved. In both interventions radiotherapy is usually part of the therapy. The sparing treatment requires a rather skillfull surgeon and radiation treatment is more complex. More than 30 comparative studies have been published, showing that the long-term survival in both treatments is equal. Morbidity of the two options is not identical (that is, different sorts of complications), but not significantly different. Numerous studies have addressed the many aspects of quality of life after mastectomy and after conservative treatment. Not surprisingly, most of these showed breast sparing to be superior. Nevertheless, no single government or financing agency has advocated the latter treatment as the therapy of choice. Instead, large differences in policy exist between different countries and regions and even in hospitals. Apart from the governments' and doctors' motives - which we will not discuss here - it should be stressed that the choice between two treatments is the patient's: since very personal and subjective feelings are at stake, she has to make a decision. Results of research on quality of life, available to the doctor, may be important for the sort of information he gives his patients (and perhaps to unbias the doctor himself), but should never direct the patient to her decision. So in this example, assessments of quality of life in formal studies are helpful in decision making, but the decisive assessment should be made by the individual patient.

Another example highlighting the importance and the difficulty of assessment of individual quality of life concerns newborns with spina bifida. In this disease, the spine is malformed and part of the marrow is dysfunctional, leading to neurological problems. Spina bifida is a relatively frequent congenital malformation, resulting in severe handicaps, such as incontinence, multiple infections, impairment of mobility (total or subtotal) and sometimes mental retardation. Thirty years ago most newborns died of early complications, such as meningitis or developing hydrocephalus. Surgical developments enabled closure of the defective spine and prevention of hydrocephalus. Moreover, advanced urologic and orthopedic interventions, among many others, increased survival considerably. Most patients suffering from spina bifida can today be prevented from dying from the disease. Mortality in the first year of life was about $80-90 \%$ until about 1955 , declined to about $30 \%$ or less in the sixtics and seventies. However, it then rose again to over $50 \%$ in recent times. Apparently, the quality of life of these patients after 'successful' operations and subsequent treatment is not very convincing and many make the very difficult decision not to embark on life-saving therapy. Such assessment includes complex moral judgements and uncertainties about prognosis. Although clinical decision making seems to be based upon the perception of (future) quality of life, the assessment is rather implicit and measurement is hardly possible.

Organisation and adjustment of support is a major reason for psycho-social diagnosis before and after heart transplantation. Heart transplantation is followed by rather complex treatment and assumes a stable and co-operative patient with a supporting social environment. However, not every patient, once transplanted, 
turns out to be very quiet and co-operative and neither the patient's lifestyle nor his family are completely dedicated to the lasting success of the transplantation all by themselves. Psychological and/or social support is usually necessary. To perform this task properly continuous assessment of the patient's quality of life is necessary and has been shown to be possible. The same, of course, applies to many major invasive treatments, requiring long-term support, but heart transplantation seems to be an example where this aspect has been carefully worked out.

\section{Levels of life?}

From the introduction and illustrative examples it may be clear how the concept 'quality of life' serves many goals and fits on many levels, perhaps with the consequence of fitting nowhere, due to its many-fold and unclear applications.

A recent report from the Health Council of The Netherlands [6] tried to clarify at least some of the conceptual problems by locating the concept in defined frameworks. Although this does not improve the clearness of the concept as such, some insight in the use of the concept and its consequences is given. We identified 4 levels in a model, described earlier by Bergsma and Duff [7]. It is primarily a practical model rather than a theoretical one.

(1) The macro level is located in societies' general, dominant religious and legal systems. The moral issue here is the more or less absolute meaning of life. As soon as life is perceived as an absolute moral value, quality of life is an issue of a value without any discussion [8]. Voluntary termination of life, for example, is just murder in this view. The moral argument is that as soon as 'quality of life' becomes an issue of discussion the relativity of life has been accepted. Practically speaking this implies that 'qualities of life' have becn related to (economical) investments in research, in human energy, in care and cure and in technological developments. Simply some qualities of life are more expensive than others and the question is clear: what is the value of these 'qualities'. This is the basis of the development of the idea 'QALYs' $[9,10]$. Termination or continuation of life is legitimated on the basis of a complex of societal values. Consequently medical ethics are not an absolute standard for medical or nursing practice anymore but a complex of values, guidelines, judgements, and suggested strategies of decision making from which life and its continuation or termination derives. After becoming a considerablc issue 'quality of life' has become comparable with economical, technical, legal or humanitarian values.

We stress the conclusion that as soon as life and its many qualities became an issue of consideration [2,3], quality of life became a political issue. Life-related issues like economical investments in education and infrastructures, or technological developments of high-tech instruments and pharmacy, are political issues and point to the necessity of weighted decisions on governmental (macro) level. Life as a moral untouchable value became an issue of considerable qualities like other considerable qualities. For some people an assault, for others a reality to live and work with. 
(2) What has been indicated as the meso level may be understood as main groups or societies, but within the health care system also as health care institutions, hospitals, nursing homes.

Health care institutions have a strong interrelatedness with society, maybe with civil initiatives, maybe with religious groups, which is still quite often the case. In the meantime there is a great variety in autonomy. This holds for their economic policy as well as for their technological (medical) policy. It is especially important for the maintaining of certain values and norms regarding their concrete health care practice. Here the same argument counts: as soon as human life is not perceived as an absolute value anymore, variations on life (qualities!) become an inescapable issue of comparison with other values. Those other values rank quite differently but vary widely. The glory of the medical team fighting for high survival rates (or low death rates), the glory of the hospital investing in new technologies, the profit of the hospital and the individual workers' salary, the research qualities of the institute, the social climate for the personnel, the well-known warm terminal care, the good relation with the bishop and his diocese are just examples of values to relate to 'qualities' of patient's life. In other words, which qualities of life are acceptable or pursuable compared with and related to values of a different nature. Important here is the fact that the acceptability of life's variations, called qualities, is the decision of the institution, no matter whether this is the board or the staff. The acceptability of life's qualities depends on the institution's goals and acceptability or pursuability of other values. Rephrasing again, differentiation in qualities depends on the patterns of decision making within the institution.

On the same level we find the patient amidst his (or her, or course) relations with relatives, friends, colleagues, partners or children. The individually-experienced quality of one's life strongly depends on the quality of those relations, the quality of school or work environment, the quality of satisfaction of basic needs, and the interrelated values people regard as their own. Literature from social health care and occupational psychology shows how strong those interrelations are and how intensely they relate to the appreciation of health and sickness. Health may be appreciated as a very important good if the interrelations are perceived as positive, illness may be perceived as a very welcome state in case of trouble at work or school. The quality people attribute to their life is not a consistent continuing attribution but varies with personal reflections on one's situation at a certain moment. The individual place within a social support system and the meaning of re lations vary between individuals but also in one individual in different episodes. Shared values influence the perception of severe illness, but also unshared values influence the perception of health and death (see also 'who decides what?'). Severe illnesses or severe accidents often isolate people from their social context. which in extreme cases implies that shared values will not be shared values any longer. Friends and relatives fear illness or death, don't dare to work together or visit the patient. They reevaluate their bonds. Many patients experience intense alienation during illness or after recovering. The perception of the quality of their life often means a cumulation of negative experiences and uncertainties which make individual prognosis on life's quality 'afterwards' quite difficult. 
(3) The personal level has been indicated as the strictly personal perception and validation of situations and circumstances. This counts for the individual patient, and this counts also for the professional frame of reference of the physician, the nurse or other health care workers. More or less depending on his group, or more or less autonomously, the patient judges his health, his illness, his future, his pain, his hope, just for himself. How does the perception of this complex of evaluation fit one's values at this moment, in this situation, how is the quality of the personal life if compared with what was experienced as normal or pursuable? How do medical decisions fit within this experiential framework, how do the personal decisions fit into the medical judgement of the situation and the decisions to be made? Because the physician is not a puppet on the institutions' string either and adds his personal values and validations to the problematic questions, he has to deal with all this, to reach decisions. This means that the ultimate decision is the individual's responsibility. Macro and meso levels have to be perceived as frameworks of sanctioning reference but nothing more, nor less.

The physicians' judgement of the patient's quality of life also and evidently depends on personal values, as mentioned earlier, but now also includes personal relationships characterized by identification, sympathy or disgust, knowledge of personal circumstances and the paticnt's hopes and wishes or denying the patient's interest. Whatever the interrelation may be, within the personal relation, considerations imply a judgement of life's quality as a value like other values, patient's values and doctor's values, and a decision based on these evaluative considerations.

In the introduction we illustrated some causes for the use of the concept quality of life. Given this basic rationale, legitimations of choices may be identified:

(a) legitimations of political decisions regarding budgets or investments;

(b) Iegitimations of technological developments;

(c) legitimation of the continuation or termination of human life; and

(d) legitimations of apparently strong interventions in individuals' lives and living, such as selection and (or) treatments.

It is quite clear that focussing on any level always requires more than subjective and intuitive consideration. The legitimation of a higher investment in nursing homes needs data which show those investments have been effective. Investment in cancer research has to be legitimated by survival data, just like the investments in transplantation technology. If morc pcople live longer the investments seem to be the right thing.

However, this statement is only true if 'life' is perceived as an absolute value. And, generally speaking on all the levels, this is not true anymore. Life shows up in gradations of quality. And, as we have seen, quality is not a number. Quality is a result of comparing and validating several values. Quality is a judgement, even a subjective judgement without a real consistency. Data can only be compared with data, quantities with quantities, measurements with measurements. But now we have one unmeasurable 'thing', a quality. First we created 'quality' as an additional legitimation. Now we do not know how to integrate this subjective notion in our system. We need 'criteria' to measure quality to 'sell' political decisions (e.g. 
on transplantation facilities), we need criteria to measure quality in order to legitimate that another medical intervention does not make 'sense' anymore, we need critcria to measure quality in order to formulate prognoses in case of selection for transplantation. The problem accounts for all the 3 levels we distinguished: quality is a judgement, a value itself, an experienced relationship, the reflection on one's existence, an inconsistent comparison, a motivation for living, but it is never a quantity. Measuring the undefinable: quantifying the quality.

There is a way out of the problem. This way out has been found if we by-pass the subjective elements in human existence and experience and just focus on those aspects of human behavior which are countable/measurable. By just observing the physical aspects of human behavior, we may find an indication for physical activities: walking, running, climbing, biking, eating, sitting, working. Those physical activities are countable and comparable, for example before and after transplantation. Therefore, a fourth level (d) is added.

(4) This is the level of physical activities. This is the level of the pure behavior, where we do not ask for judgements, for experiencing quality, but just observe and count. For physical behavior we can develop criteria and operationalisations, we can count, measure and subsequently calculate parameters. We can formulate hypotheses fitting the quantitative frame of reference and formulate prognoses. Literature shows that this way of doing research, and this way for legitimation of investments and developments on different levels, can be fruitful. The only remark is that this reduction of human existence to physical behavior does not allow us to come to conclusions about the concept 'quality of life'. Strictly it would be incorrect to use the term 'quality of life' if considering these kinds of measurements.

'Quantities of life' might be closer to what is being observed.

\section{Measurement and description}

Measurement of what has been labeled as quality of life on what we have designated the fourth level (physiological possibilities), has been carried out for many years and for many purposes. The well-known Karnovsky scale, for instance, was originally devised to establish the need for nursing care. Although this instrument has also frequently been used as an index for well-being, the prognostic valuc is very small in most cases studied. To some extent a quantitative instrument, the Karnovsky scale is limited to physical performance as such and does not aim at measuring happiness, relations, behavior, etc. The Karnovsky rating is a rough rating made by the doctor. Similar instruments exist, more or less tuned to specific goals, such as the 'ADL-scale' in The Netherlands ('Activities of Daily Living') and the classification of the New York Heart Association. The latter (NYHA-)scale has frequently been used as an assessment of the validity of heart patients and serves as an index for the state of progression of the illness or for therapeutic results.

Psychology has yielded many methods of assessment. In a number of those, numeric results aim at objective and quantitative measurements of areas such as anx- 
iety, relations, self-esteem, optimism, cooperation, etc. Well-known examples are the Nottingham Health Profile, the 'index of psychological affect', 'The quality of American life' and many others. The field of socio-oncologic research has resulted in many instruments, several of which could be demonstrated to give reproducible results $[11,12]$. The recently created WHO Collaborating Centre for Research into Quality of Life (Amsterdam) may become one of the crystallisation points for this approach.

Measurement is confined to the measurable. Numbers can only illustrate what can be expressed in numbers of ratings. It is not without risk to degrade qualities to quantities. Measurement of 'quality of life' inevitably reduces life itself to something like 'How much physical life is still present?'. Nevertheless, these measurements can provide important information. But it is often difficult, if not impossible, to get to its real significance within a certain specific context. Thorough descriptions of their different contents, no matter whether it is the patients' family life or the hospital setting, will remain a condition for a realistic validation of the results of measurements. Descriptive research has to be seen as conditional as well as a method we cannot do without in this area to keep the judgements in balance.

So, does measurement of quality of life help? Yes, it can. Does assessment of quality of life give any aid in decisions? Yes, possibly. In our final paragraph a view on clinical decision making is presented.

\section{Who decides what?}

'If biological life is medicine's goal, then the patient should be kept alive as long as possible. If the preservation of autonomy is the goal of medicine, then one must do everything possible to maintain the integrity of the person in the face of death'. Cassell [13] expresses in brief the dilemma of quality of life and related decision making. If life is an absolute moral value for the physician, there is no discussion. If the patient wants it another way, he has to choose another doctor, otherwise life will go on as long as technology prescribes. The other extreme is the patient who decides not to live any longer or does not want any treatment, whatever the motives are. It may be clear that such absolute regimes are quite exceptional, but this also implies that in the majority of cases the solution is less clear. And this solution is always situated, whatever the preconditions and limitations may be, in the doctor-patient relationship. Within this relationship 'quality of life' is one of the issues in the decisions concerning cure and care.

We distinguish 3 modes of relationship: the first mode where the physician is the one who decides, the second one where the patient decides, and the third one where we find open communication and deliberations.

In the first mode the doctor takes the responsibility (or the responsibility is given to him), to decide on the basis of relevant information regarding the patient, the disease and its prognosis. Some situations may be characterized as authoritative when the doctor is coercive, takes decisions or makes the patient decide without sufficient relevant information and insight in his own situation. In many of those 
cases, even when the patient states that 'doctor knows best', quality of life is not the first or the most important issue to be recognized. In interviews with doctors some of them told us how difficult it is to withhold this pressure from the patient, for instance when he is the last patient needed in a trial. More or less comparable, but with much more attention to the patient's quality of life, is this kind of relationship labeled as 'paternalistic'. Here we may observe the same kind of pressure on the patient, but the intention is different, because (for example) the physician estimates that the patients' quality of life will improve after some intervention. Here the physician may become coercive but from the idea that he really 'knows better', for instance in a case where the patient refuses chemotherapy for testis carcinoma and the physician knows the quality of life of this patient may improve remarkably after this aggressive therapy. This attitude is also oppressive but the intentions are different. Nevertheless, in both cases the patient's autonomy has not been recognized by the decision to withhold the freedom of choice or the relevant information. The ethical question here is how much autonomy is left for the physician. being chained by the responsibility for the patient's life and living $[14,15]$.

A second option is the one where the patients' judgement of his or her own quality of life is decisive and the physicians' interests become of minor importance. The patient 'rules the waves' and the physician is the subordinate only being responsible for the execution of the decision. This situation is less exceptional than may be thought since the non-directive attitude in many physicians' training became a central philosophy.

Examples such as medical shopping, abortion, in vitro fertilization or allowing death to occur underline the difference in ethical levels related to these kinds of decisions. Important here is to stress that patients' autonomy seems to have priority but is limited by the physicians' willingness and responsibility. It is at least a heavily restricted autonomy regardless of the ideas of the physician.

The third kind of relationship is not only characterized by openness but especially by mutual respect for each others' autonomy. This means an open consideration of the factual situation and its perspectives, acceptance of the judgement of the actual 'quality of living' and availability of relevant information for both partners [16]. An autonomous choice can only be met by an autonomous respect and acceptance of this decision, an influential relationship, a discourse or dialectic crystallisation of a decision without the coercive character of the other two options. Elsewhere we explored this relation extensively, labeling it as 'shared autonomy' [15].

Cassell [13] suggests in the above-cited sentences two ways to a decision. In the first one - mere continuation of life - quality of life is no determinant in the decision making. In the second one - preservation of personal integrity - it seems to us that only the mutual respect for autonomy can facilitate a real choice based on an honest judgement and real interpretation of available information. In this way an autonomous consideration of choices is the main condition for a decision which docs not affect the integrity.

The conclusion is: the patient decides about the consequences of the subjective judgement of his or her quality of life, but in many cases this patient needs an au- 
tonomous partner to clarify and legitimate his own judgement and its consequences. Often the physician has the privileged chance to be this partner. Personal choices have to become personal decisions, generated within personal relationships.

\section{References}

1 Strauss, A.L., Chronic illness and the Quality of Life, Mosby, St. Louis, 1975.

2 Berg, J.H. van den, Medische Macht en Medische Ethiek, Callenbach, Nijkerk 1965.

3 Duff, R.S. and Campbell, A.G.N., Moral and ethical dilemmas in special care nursery, The New England Journal of Medicine, 299, (1973) 890-893.

4 Charro, F. de and Banta, H.D., Transplant policy in the Netherlands. International Journal of Technology Assessment in Health Care, 2 (1986) 533-544.

5 Charro, F. de, Kosten-effectiviteitsanalyse van het nierfunctievervangingsprogramma in Nederland, Thesis, Rotterdam, 1988 (ISBN 90-5166-018-9).

6 Health Council of The Netherlands, Transplantation, 's-Gravenhage, 1987.

7 Bergsma, J. and Duff, R.S. A model for examining values and decision making in the patient-doctor relationship, The Pharos of Alpha, 43 (1980) 7-12

8 Musschenga, A.W., Kwaliteit van Leven, Ambo, Baarn, 1987.

9 Williams, A., The Value of 'Qalys', Health and Social Service Journal, 6 (1985).

10 Williams, A., Who is to live? A question for the econonist or the doctor? World Hospitals, 23 (1987) 34-36.

11 Aaronson, N.K., Quantitative issues in health-related quality of life assessment, Health Policy, 10 (1988) 217-230.

12 Selby, P. and Robertson, B., Measurement of quality of life in patients with cancer, Cancer Surveys, 6 (1987) 521-543.

13 Cassell, E., The function of medicine, Hastings Center Report, 7 (1977) 16-19.

14 Bergsma, J., Towards a concept of shared autonomy, Theoretical Medicine, 5 (1984) 325-331.

15 Bergsma, J., Identiteit, lichamelijke verstoring en autonomie, De Tijdstroom, Lochem, 1987.

$16 \mathrm{Katz}$, J., The Silent World of Doctor and Patient, Free Press, New York 1981. 